\title{
Half-height Pins - a New Pin Form in Gap Waveguide for Easy Manufacturing
}

\author{
Fangfang Fan ${ }^{1,2}$, Jian Yang ${ }^{2}$ and Per-Simon Kildal ${ }^{2}$ \\ ${ }^{1}$ The Science and Technology on Antenna and Microwave Laboratory, Xidian University, Xi'an, China \\ ${ }^{2}$ Dept. of Signals and Systems, Chalmers University of Technology, S-412 96 Gothenburg, Sweden \\ E-mail: fangfang.fan@chalmers.se, jian.yang@chalmers.se, per-simon.kildal@chalmers.se
}

\begin{abstract}
Gap waveguide is a promising transmission structure, especially for millimeter wave and $\mathrm{THz}$ applications. It does not require conductive connection between the top and bottom plates, and therefore this technology gain advantages over conventional rectangular waveguides and SIWs (Substrate Integrated Waveguides) above $100 \mathrm{GHz}$. In this paper, a new pin form, the half-height pin, is proposed for the gap waveguide. This new half-height pin form has similar stop-band performance as the previous quarter-wavelength long pin form. However, there must be such half-height pins on both the upper and lower plates, in contrast to one of the two having pins in the original gap waveguide. The shorter length of the pins makes the fabrication of the pin surface much easier, such as by e.g. die-forming, molding or MEMS technology. The current work paves the way for mass production of gap waveguide devices and systems at millimeter wave and THz.
\end{abstract}

Index Terms-gap waveguide, half-height pin, stop-band bandwidth.

\section{INTRODUCTION}

The gap waveguides [1] are realized in the gap between two parallel metal plates, with periodic metal pins on the bottom plate to play the role of an AMC (Artificial Magnetic Conductor), and with a smooth surface on the metal top plate working as a PEC (Perfect Electrical Conductor). No electromagnetic waves can propagate in the gap, except along some guiding structures, such as ridges in the ridge gap waveguides and grooves in the groove gap waveguides, and only under the condition that the gap between the top of the pins and the top plate is smaller than a quarter wavelength. Since the waves only propagate through air, there is no dielectric losses. Thus, the gap waveguides have the advantage of lower loss than microstrip lines and SIWs (Substrate Integrated Waveguide), where the waves propagate in dielectric materials. In addition, we can use larger transverse dimensions than in microstrip lines, and therefore the conductive losses will also be smaller. Till now, several gap waveguide antennas array [2]-[6] and components, such as coupler, filter and power divider [7] [14] have been designed with good performance, and the gap waveguide has also been shown to be capable of packaging passive and active components realized with other transmission line or waveguide technologies [15].

The fact that the gap waveguide does not require conductive connection between the top and the bottom plates opens up for more cost-effective manufacture methods to be used in millimeter wave and $\mathrm{THz}$ applications.
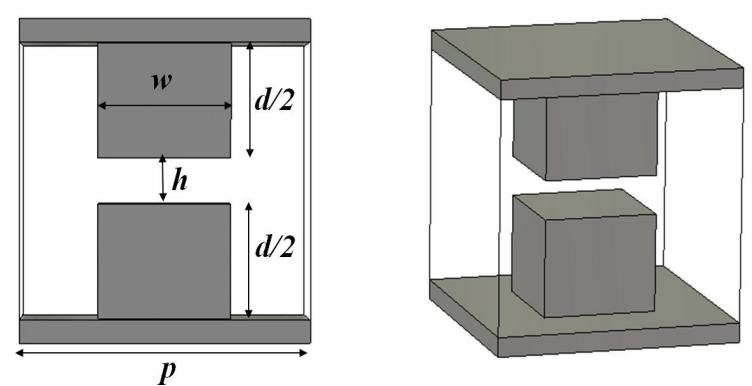

Fig. 1. Half-height pin form for gap waveguide technology.

The parallel-plate stop-band of gap waveguides are most often realized by periodic pins, although many other periodic structures can also be used [16]-[18]. Different pin forms are possible, such as square pins [1], circular pins [16], the inverted pyramid-shaped pins [17] and the double cone pins [18]. The first two are the basic forms and the last two are the variations for wideband applications. However, all forms require in principle close to quarter-wavelength long pins. Such long pins may cause some problems for fabrication, especially for mass production. Therefore, a shorter pin form is preferred. In the current paper, we propose half-height pin form in both plates to reduce the fabrication difficulty, instead of the full-height pins in one of them. We analyze carefully the stop-band characteristics of the new pin form at $\mathrm{Ka}$ and $\mathrm{V}$ bands, and we design and simulate a ridge gap waveguide with half-height pins and two $90^{\circ}$ bends for verification.

\section{Geometry of the New Pin Form And Its STOP-BAND CHARACTERISTIC}

A unit cell of the half-height pin is shown in Fig. 1. It has an air gap $h$ between the upper and the lower pins. The optimal value of the pin's length is about half of the regular pins, which is the reason for its name, denoted as $d / 2$. The width of the pin is $w$, then is the period $p$ of the half-height pin. With the aid of the Eigenmode slover in CST [19], we investigate how the parameters affects the stop-band characteristic of the half-height pin. Fig. 2 gives the dispersion diagram of a ridge gap waveguide with half-height pins as shown in Fig. 2(a). Here the ridge is also of half-height, so the gap waveguide is actually a double ridge gap waveguide. From Fig. 2(b), 


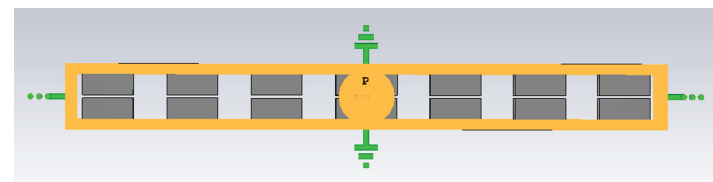

(a) The model of the ridge with period pins.

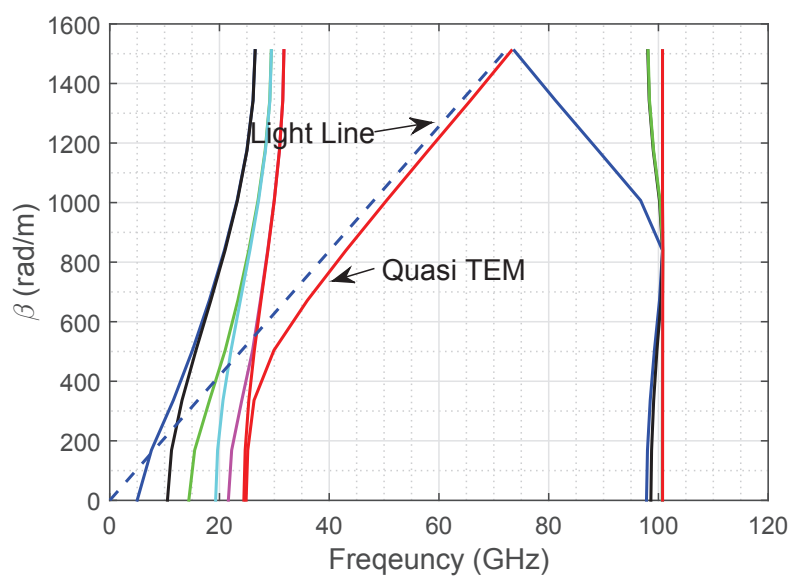

(b) The dispersion diagram.

Fig. 2. Dispersion diagram of the double ridge gap waveguide with halfheight pins, where $p=2.08 \mathrm{~mm}, d=1.39 \mathrm{~mm}, h=0.07 \mathrm{~mm}, w=1.25$ $\mathrm{mm}$

we can see that the double ridge gap waveguide has a single dominate (basic) mode propagation band over 31.8-73.2 GHz, and the propagation mode is a Quasi-TEM mode because its propagation parameter follows that of the light line.

\section{Double-Bend TRANSMission Line Design AND THE TRANSITION to STANDARD WAVEGUIDES}

To verify the transmission characteristic of the gap waveguide with new half-height pin form, double ridge gap waveguide with two $90^{\circ}$ bends has been designed. Fig. 3 is the geometry of the transmission line with the two $90^{\circ}$ bends. Here, the waveport used in CST is defined as the width $p w$ and the height $p h$, where $p w$ is set as the width of the ridge and plus the spacing to the closest pins on either side, $p h$ is the height of the double ridge and the air gap between them, and for these parameters, good transmission can be obtained. The simulated S parameters are plotted in Fig. 4 and 2D color figures showing the vertical E field distribution between the upper and lower ridges are plotted in Fig. 5. As shown in the figure, the field follows the ridge very well from $30-70 \mathrm{GHz}$. Fig. 6 shows the S parameters of two $90^{\circ}$ bends transmission line with regular pins, which has the same dimension with the half-height pins. It can be concluded they have very similar transmission characteristic.

Considering the measurement, we need transitions from standard waveguides to the double ridge gap waveguide with two $90^{\circ}$ bends. Since the operation bandwidth for the gap waveguide is from $31.8-73.2 \mathrm{GHz}$, we need two transitions to different standard waveguides: one to $\mathrm{Ka}$ band standard

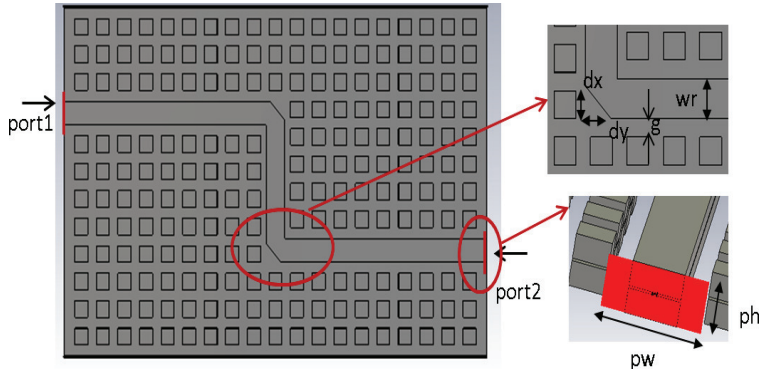

Fig. 3. Geometry of the double ridge gap waveguide with two $90^{\circ}$ bends based on half-height pins, where $w r=1.8 \mathrm{~mm}, g=0.83 \mathrm{~mm}, d x=d y=$ $1.45 \mathrm{~mm}$. Note that the upper half is hidden for clear presentation.

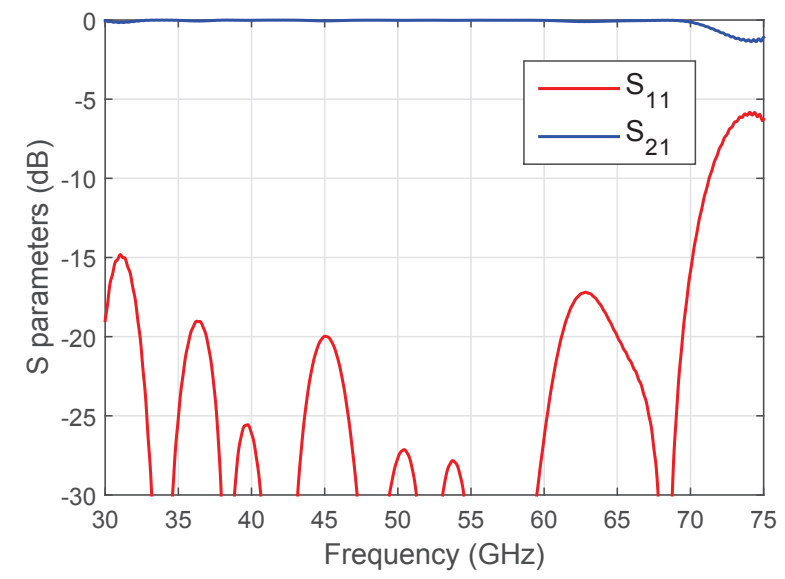

Fig. 4. The simulated $\mathrm{S}$ parameters for the double ridge gap waveguide with two $90^{\circ}$ bends based on half-height pins.

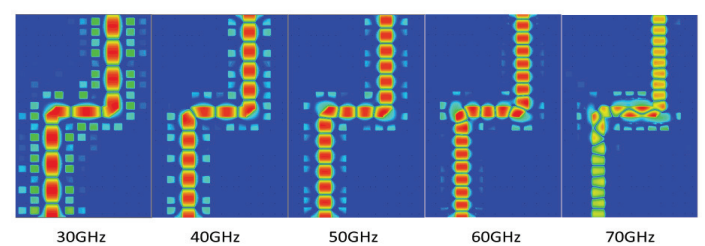

Fig. 5. The field distribution of the double ridge gap waveguide with two $90^{\circ}$ bends based on half-height pins at different frequencies.

waveguide WR-28 and the other to $\mathrm{V}$ band standard waveguide WR-15. For the Ka band transition, it is not easy to get good results by simple direct transformation of the geometry since the size of the gap waveguide will make the dominate modes at Ka band below cutoff. We tried several different transitions, and finally we chose a polynomial function profile for the ridge and cavity as shown in Fig. 7(a). This gave good matching. The simulated results for this transition are shown in Fig. 8(a), where the reflection coefficient $\left(S_{11}\right)$ is lower than $-13 \mathrm{~dB}$ over the whole Ka band. For the $\mathrm{V}$ band transition, four stepped ridges are used, and then the height is changed to the standard waveguide by tapering, as shown in Fig. 7(b). Fig. 8(b) is the 


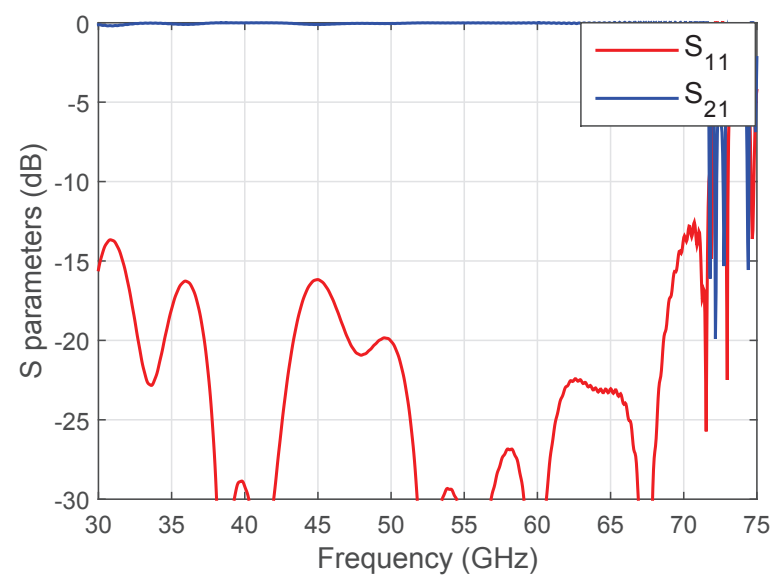

Fig. 6. The simulated $\mathrm{S}$ parameters for the double ridge gap waveguide with two $90^{\circ}$ bends based on full-height pins.

final results for $\mathrm{V}$ band transition and the reflection coefficient reaches below $-14 \mathrm{~dB}$ within the transmission band. All the values of the parameters are given in Table I.

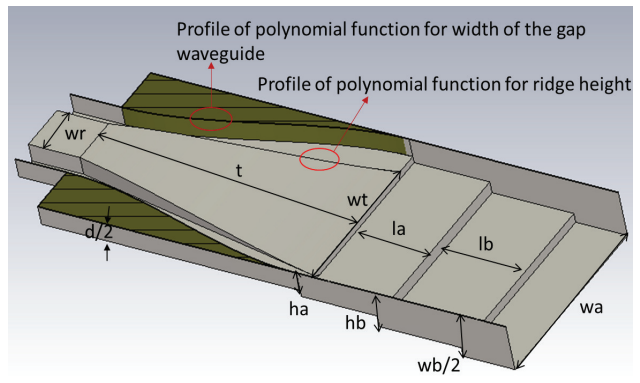

(a) Ka band transition.

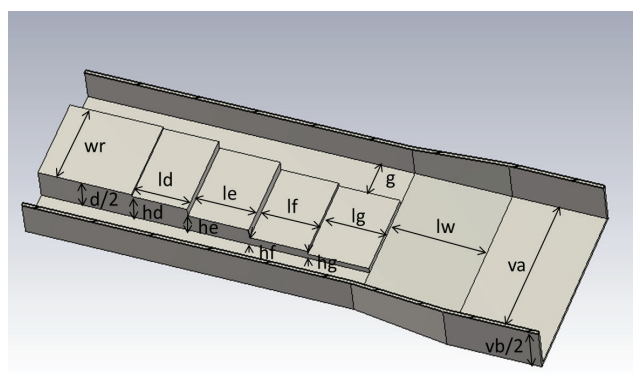

(b) V band transition.

Fig. 7. Two transitions from the half-height ridge gap waveguide in Fig. 3 to standard waveguides WR-28 and WR-15. Note that the upper half is hidden for clear presentation.

After connecting the double ridge transmission line in Fig. 3 with the $\mathrm{V}$ band transition in Fig. 7(b), we get the results shown in Fig. 9, it can be seen that the reflection coefficient reaches below $-8 \mathrm{~dB}$ within the transmission band.

We are making a prototype for measurement to verify the simulated results.

In addition, we also have done some simulation work about the sensitivity for alignment of the top and bottom layer pins.

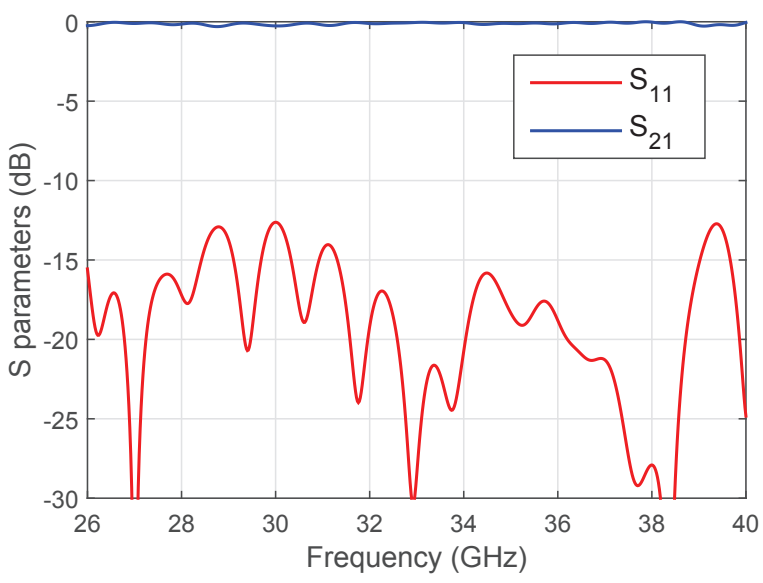

(a) Ka band transition.

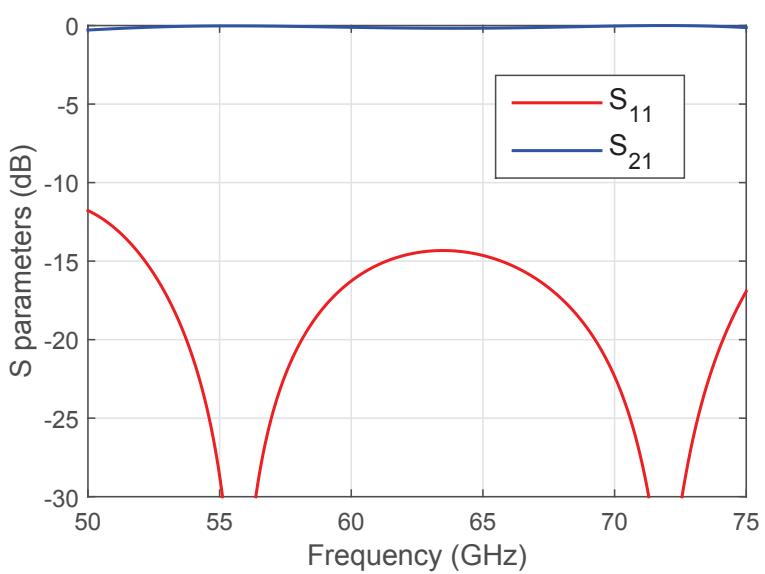

(b) V band transition.

Fig. 8. Simulated results for the Ka and $\mathrm{V}$ band transitions.

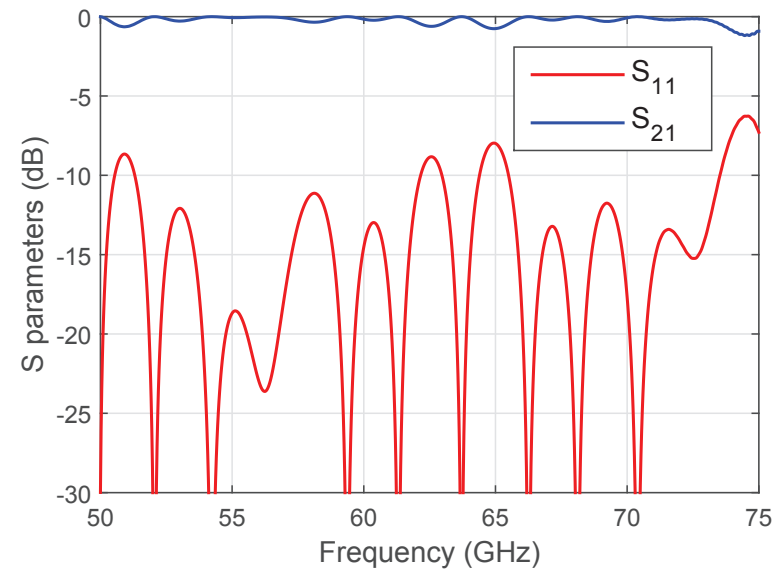

Fig. 9. The simulated $\mathrm{S}$ parameters for double ridge gap waveguide with two $90^{\circ}$ bends with $\mathrm{V}$ band transition.

If the alignment offset distance is less than $0.1 \mathrm{~mm}$, it will not influence the transmission performance. Later we will do this 
experiment to verify it.

TABLE I

THE PARAMETER VALUES FOR FIG. 7

\begin{tabular}{c|c|c|c|c|c|c}
\hline \hline Parameter & $l a$ & $l b$ & $h a$ & $h b$ & $t$ & $w t$ \\
\hline Value $(\mathrm{mm})$ & 2.92 & 3.15 & 0.98 & 1.58 & 40.1 & 5.5 \\
\hline Parameter & $l c$ & $l d$ & $l e$ & $l f$ & $v a$ & $v b$ \\
\hline Value $(\mathrm{mm})$ & 1.18 & 1.29 & 1.22 & 1.30 & 3.76 & 1.88 \\
\hline Parameter & $h c$ & $h d$ & $h e$ & $h f$ & $w a$ & $w b$ \\
\hline Value $(\mathrm{mm})$ & 0.64 & 0.45 & 0.22 & 0.13 & 7.11 & 3.56 \\
\hline \hline
\end{tabular}

\section{CONCLUSION}

A new pin form, referred to as the half-height pin, in gap waveguide technology has been presented. It has a similar stop-band characteristic as the previous regular full-height metal pin used in gap waveguide technology, but half-height pins must be provided at both the upper and lower surfaces, not only one of them as in the regular gap waveguide. This reduced height can reduce the fabrication difficulty, especially for mass production. A double ridge gap waveguide with halfheight pins has been designed for verification. The simulated results showed that the ridge gap waveguide with the new pin form has the similar performance as that of the ridge gap waveguide with regular pins. Thus, this new pin form provides a flexibility of choosing different pin forms in gap waveguide technology for low-cost manufacture.

The half-height pin gap waveguide is protected by a pending patent [20].

\section{ACKNOWLEDGMENT}

This work has been supported by the Natural Science Foundation of China (NSFC) under Grant 61301068, the Fundamental Research Funds for the Central Universities (JB150207), the European Research Council (ERC) via an advanced investigator grant ERC-2012-ADG_20120216 and Swedish Governmental Agency for Innovation Systems (VINNOVA) within the VINN Excellence Center Chase at Chalmers.

\section{REFERENCES}

[1] P.-S. Kildal, E. Alfonso, A. Valero-Nogueira, and E. Rajo-Iglesias, "Local metamaterial-based waveguides in gaps between parallel metal plates," IEEE Antennas and Wireless Propagation Letters, vol. 8, pp 84-87, 2009

[2] E. Pucci, E. Rajo-Iglesias, J.-L. Vazquez-Roy, and P.-S. Kildal, "Planar dual-mode horn array with corporate-feed network in inverted microstrip gap waveguide," Antennas and Propagation, IEEE Transactions on, vol. 62, no. 7, pp. 3534-3542, 2014.

[3] A. U. Zaman and P.-S. Kildal, "Wide-band slot antenna arrays with single-layer corporate-feed network in ridge gap waveguide technology," Antennas and Propagation, IEEE Transactions on, vol. 62, no. 6, pp. 2992-3001, 2014.

[4] M. Al Sharkawy, A. Kishk et al., "Wideband beam-scanning circularly polarized inclined slots using ridge gap waveguide," Antennas and Wireless Propagation Letters, IEEE, vol. 13, pp. 1187-1190, 2014.

[5] A. U. Zaman and P.-S. Kildal, "A new $2 \times 2$ microstrip patch subarray for $60 \mathrm{GHz}$ wideband planar antenna with ridge gap waveguide distribution layer," in Antennas and Propagation (EuCAP), 2015 9th European Conference on. IEEE, 2015, pp. 1-4.
[6] A. U. Zaman, J. Yang, and P.-S. Kildal, "Using lid of pins for packaging of microstrip board for descrambling the ports of eleven antenna for radio telescope applications," in Antennas and Propagation Society International Symposium (APSURSI), 2010 IEEE. IEEE, 2010, pp. $1-4$.

[7] J. Yang and H. Raza, "Empirical formulas for designing gap-waveguide hybrid ring coupler," Microwave and optical technology letters, vol. 55, no. 8, pp. 1917-1920, 2013.

[8] M. S. Sorkherizi, A. Khaleghi, and P.-S. Kildal, "Direct-coupled cavity filter in ridge gap waveguide," IEEE Transactions on Components, Packaging and Manufacturing Technology, vol. 4, no. 3, pp. 490-495, 2014.

[9] E. A. Alos, A. U. Zaman, and P. Kildal, "Ka-band gap waveguide coupled-resonator filter for radio link diplexer application," IEEE Transactions on Components, Packaging and Manufacturing Technology, vol. 3, no. 5, pp. 870-879, 2013.

[10] A. U. Zaman, P.-S. Kildal, A. Kishk et al., "Narrow-band microwave filter using high-Q groove gap waveguide resonators with manufacturing flexibility and no sidewalls," IEEE Transactions on Components, Packaging and Manufacturing Technology, vol. 2, no. 11, pp. 1882-1889, 2012 .

[11] A. Berenguer, M. Baquero-Escudero, D. Sanchez-Escuderos, B. Bernardo-Clemente, and V. E. Boria-Esbert, "Low insertion loss 61 $\mathrm{GHz}$ narrow-band filter implemented with groove gap waveguides," in 2014 44th European Microwave Conference (EuMC). IEEE, 2014, pp. 191-194.

[12] A. del Olmo-Olmeda, M. Baquero-Escudero, V. E. Boria-Esbert, A. Valero-Nogueira, and A. J. Berenguer-Verdu, "A novel band-pass filter topology for millimeter-wave applications based on the groove gap waveguide," in 2013 IEEE MTT-S International Microwave Symposium Digest (IMS). IEEE, 2013, pp. 1-4.

[13] H. Raza, J. Yang, P.-S. Kildal, and E. Alfonso Alos, "Microstrip-ridge gap waveguide-study of losses, bends, and transition to WR-15," IEEE Transactions on Microwave Theory and Techniques, vol. 62, no. 9, pp. 1943-1952, 2014.

[14] H. Raza and J. Yang, "Compact UWB power divider packaged by using gap-waveguide technology," in 2012 6th European Conference on Antennas and Propagation (EUCAP). IEEE, 2012, pp. 2938-2942.

[15] A. U. Zaman, M. Alexanderson, T. Vukusic, and P.-S. Kildal, "Gap waveguide PMC packaging for improved isolation of circuit components in high-frequency microwave modules," Components, Packaging and Manufacturing Technology, IEEE Transactions on, vol. 4, no. 1, pp. 16-25, 2014

[16] E. Rajo-Iglesias and P.-S. Kildal, "Numerical studies of bandwidth of parallel-plate cut-off realised by a bed of nails, corrugations and mushroom-type electromagnetic bandgap for use in gap waveguides," IET microwaves, antennas \& propagation, vol. 5, no. 3, pp. 282-289, 2011.

[17] A. U. Zaman, V. Vassilev, P.-S. Kildal, and A. Kishk, "Increasing parallel plate stop-band in gap waveguides using inverted pyramid-shaped nails for slot array application above 60GHz," in Proceedings of the 5th European Conference on Antennas and Propagation (EUCAP). IEEE, 2011, pp. 2254-2257.

[18] S. Shams and A. Kishk, "Double cone ultra wide band unit cell in ridge gap waveguides," in 2014 IEEE Antennas and Propagation Society International Symposium (APSURSI). IEEE, 2014, pp. 1768-1769.

[19] CST Microwave Studio; http://www.cst.com.

[20] J. Yang and F. Fan, "Waveguides and transmission lines in gaps between parallel conducting surfaces (half-height pins and double period pins in both surfaces) ," European Patent Application EP-15186666.2, Gapwaves AB Sweden, 24 September 2015. 